\title{
Effect of Soaking Period of Clay on its California Bearing Ratio Value
}

\author{
Robert Nini ${ }^{1}$ \\ ${ }^{1}$ University of Balamand \\ Balamand, Lebanon \\ Robert.nini@balamand.edu.lb
}

\begin{abstract}
The quality of road pavement is affected mostly by the type of sub-grade which is acting as road foundation. The roads degradation is related to many factors especially the climatic conditions, the quality, and the thickness of the base materials. The thickness of this layer depends on its California Bearing Ratio (CBR) test value which by its turn is highly affected by the quantity of water infiltrated under the road after heavy rain. The capacity of the base material to drain out its water is predominant factor because any change in moisture content causes change in sub-grade strength. This paper studies the effect of the soaking period of soil especially clay on its CBR value. For this reason, we collected many clayey samples and on each soil, two groups of experiments were performed: main tests consisting of Proctor and CBR test from one side and from other side identification tests consisting of other tests such as Atterberg limits tests. Each soil sample was first subjected to Proctor test in order to find its optimum moisture content which will be used to perform the CBR test. Four CBR tests were performed on each soil with different soaking period. The first CBR was done without soaking the soil sample; the second one with two days soaking, the third one with four days soaking period and the last one was done under eight days soaking. By comparing the results of CBR tests performed with different soaking time, a more detailed understanding was given to the role of the water in reducing the CBR of soil. In fact, by extending the soaking period, the CBR was found to be reduced quickly the first two days and slower after. A precise reduction factor of the CBR in relation with soaking period was found at the end of this paper.
\end{abstract}

Keywords: California bearing ratio, clay, proctor test, soaking period, sub-grade.

\section{Introduction}

The water content of a fine grained soil as clay has a significant effect on its strength and on its compressibility characteristics [1]. In fact, the stiffness of the clayey sub-grade layer depends on its humidity. The clay with its very weak permeability [2] is found to be more affected by the water presence than the other types of soils. Surface and subsurface drainage of road pavement and from adjoining land also affect significantly sub-grade strength [3].This gives a high importance on the effect of the soaking period on the CBR value of soil. Many researchers tried to increase the CBR of soaked clay by adding fibers [4] or by adding geogrids for the sub-grade [5]. The objective of this research paper is to find the reduction ratio of CBR value of clay relatively to a proposed number of soaking days. Logically, we started by un-soaked clay CBR which will be the basic state for our comparison. To achieve our goal, we collected nine clayey samples from different Lebanese zones. These soils were subjected to two set of experiments, the main experiments and the identification experiments. The main experiments are the Proctor and the CBR test. In fact, the Modified Proctor test was performed in order to find the optimum moisture content OMC of the soil giving the maximum dry density MDD which will be used to compact the soil for the CBR test. After it, four sets of CBR test were done. The first CBR was done on the soil without soaking it. The second CBR was performed after soaking the sample for two days in water. The third one is soaked according to ASTM requirement which is four days. The last one was soaked for eight days. After this, the identification tests such as Atterberg limits were performed in order to classify the soils.

\section{Experiments and results}

All the soil experiments performed in this section are done by following the American Society for Testing and Materials (ASTM) standards. In order to obtain consistent results, we worked on different clayey samples to get credible and objective results. For this reasons, nine samples of clayey soils were collected from different locations in Lebanon. The samples are extracted from Barja, Sahel Akkar, Ghazieh, Minieh, Machta Hasan, Saida, Abi Samra, Anfeh and Batroumin. 


\subsection{Modified Proctor test}

After computing the water content of the soil samples when arrived to laboratory, we performed the Modified Proctor test according to ASTM Standard D1557-12 [6]. The results are presented in Fig. 1 and the maximum dry density MDD and the corresponded optimum moisture content \% OMC for the nine soil samples are grouped in Table I. The molds used in this test have a diameter of $101.6 \mathrm{~mm}$. Five layers of soil were used in each mold.

\subsection{CBR test}

Once the Modified Proctor tests were done, we performed the CBR test on soils compacted under OMC according to ASTM Standard 1883 [7]. Four set of CBR were performed on each soil sample. The difference between these four CBR are the soaking period which ranged between un-soaked soil, two days soaked, four days soaked and finally eight days soaked. These tests are done to reveal the effect of the soaking period on the CBR of soils. The four CBR tests for each soil are presented as curves on the same figure. We plotted all the CBR curves for seven soils in Figs.2-10

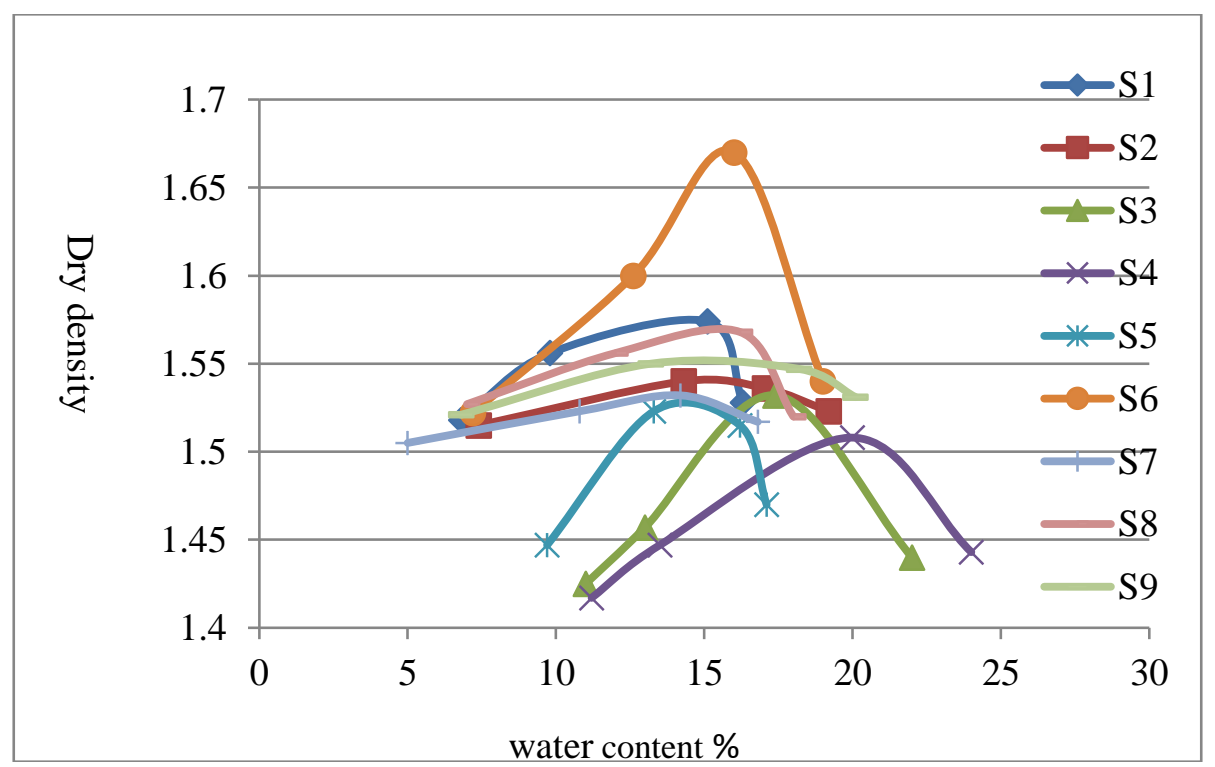

Fig. 1: Modified Proctor tests performed on nine sample.

Table 1: Modified Proctor test results.

\begin{tabular}{|c|c|c|c|}
\hline Soils & Location & $\begin{array}{c}\text { Optimum Moisture Content } \\
\text { OMC \% }\end{array}$ & $\begin{array}{c}\text { Maximum Dry Density } \\
\text { MDD }\end{array}$ \\
\hline S1 & Barja & 15.0 & 1.575 \\
\hline S2 & Sahel Akkar & 15.5 & 1.542 \\
\hline S3 & Ghazieh & 17.2 & 1.53 \\
\hline S4 5 & Minieh & 20.1 & 1.508 \\
\hline S6 & Mashta Hasan & 14.5 & 1.53 \\
\hline S7 & Saida & 14.2 & 1.54 \\
\hline S8 & Abi Samra & 13.5 & 1.631 \\
\hline
\end{tabular}




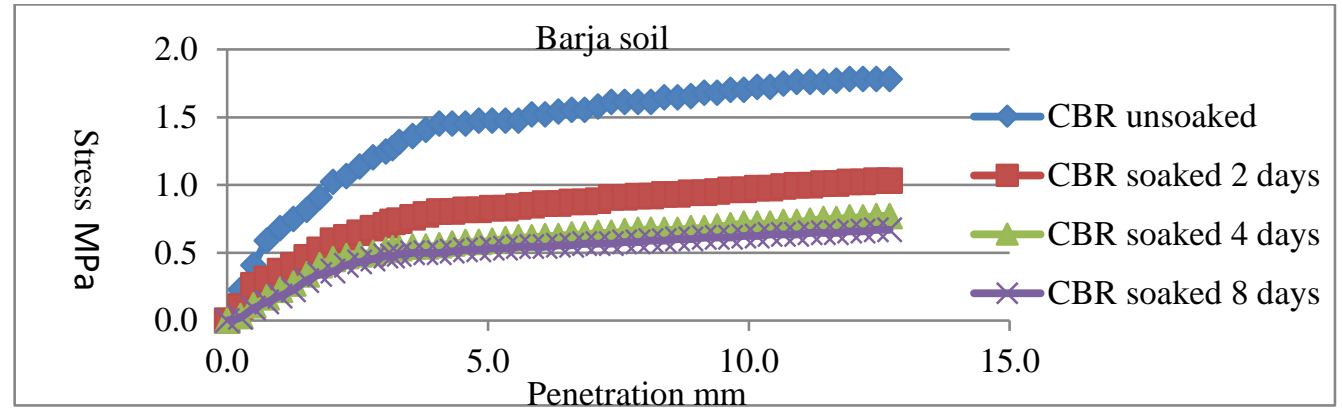

Fig. 2: CBR with different soaking periods on Barja soil.

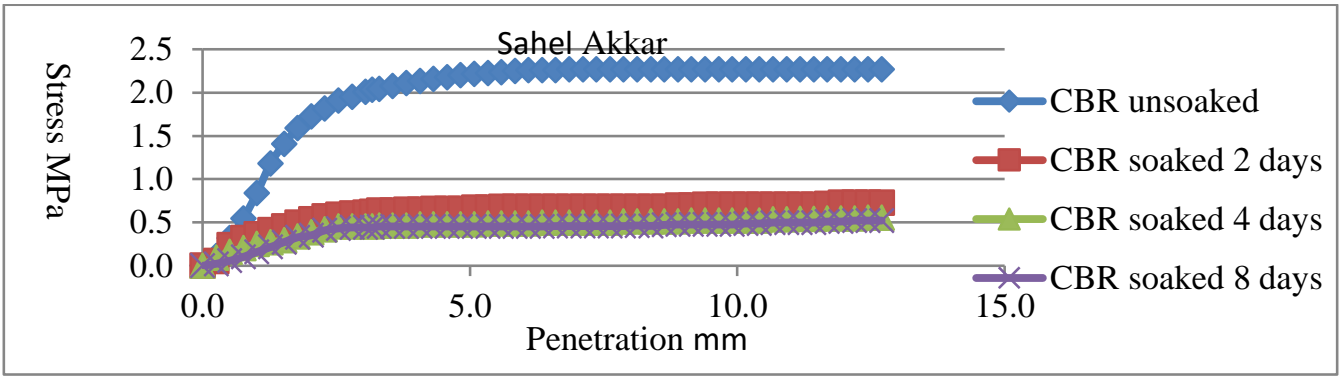

Fig. 3: CBR with different soaking periods on Sahel Akkar soil.

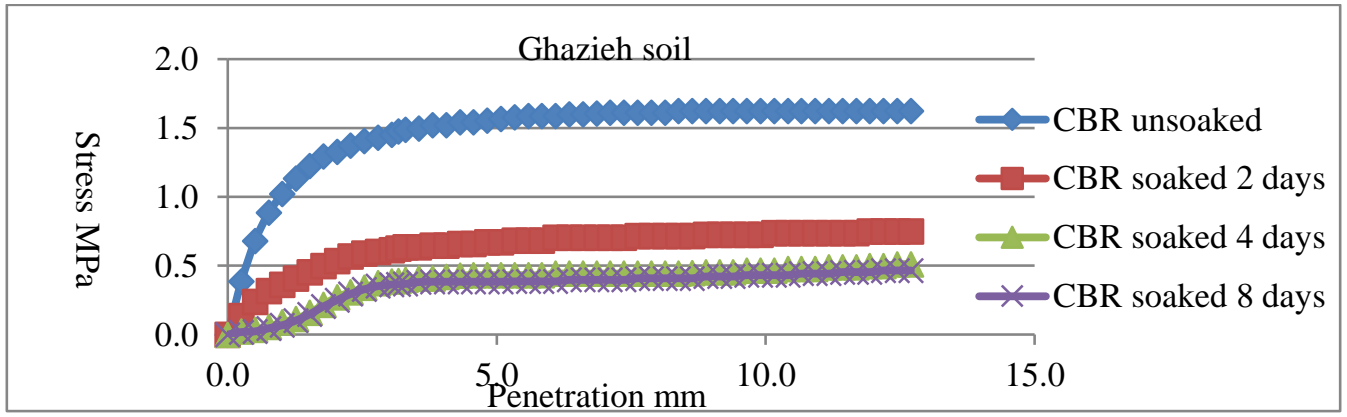

Fig. 4: CBR with different soaking periods on Ghazieh soil.

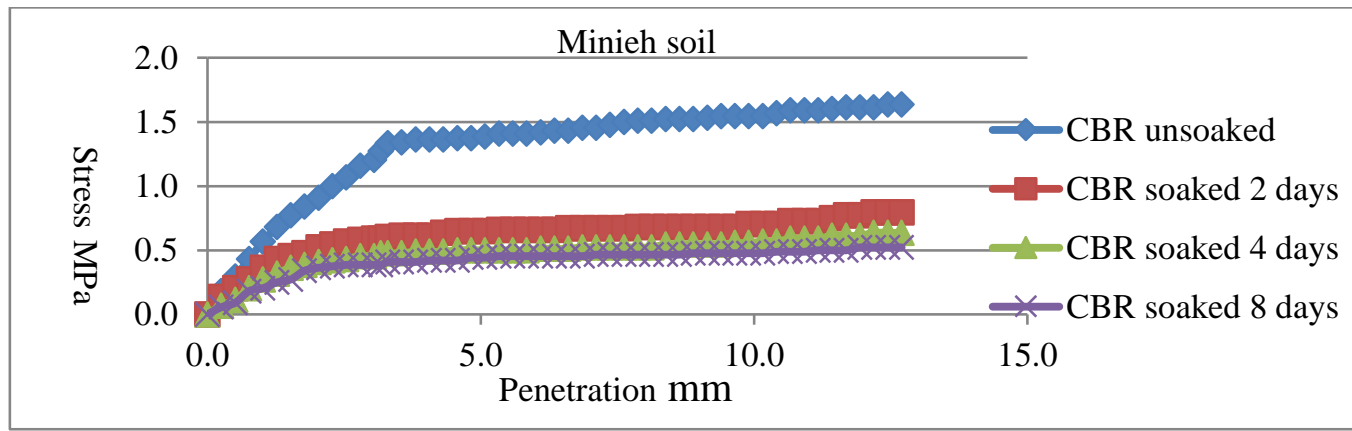

Fig. 5: CBR with different soaking periods on Minieh soil. 


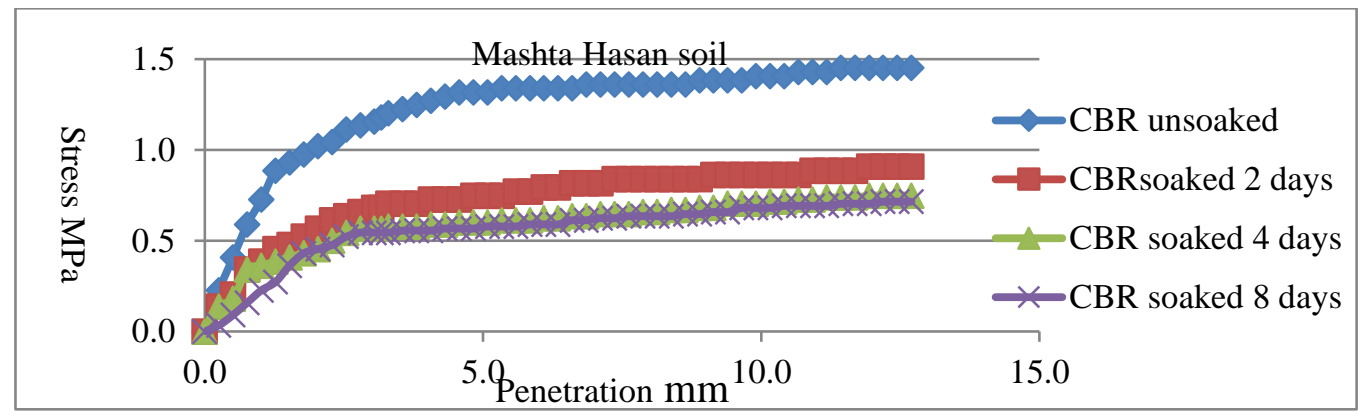

Fig. 6: CBR with different soaking periods on Mashta Hasan soil.

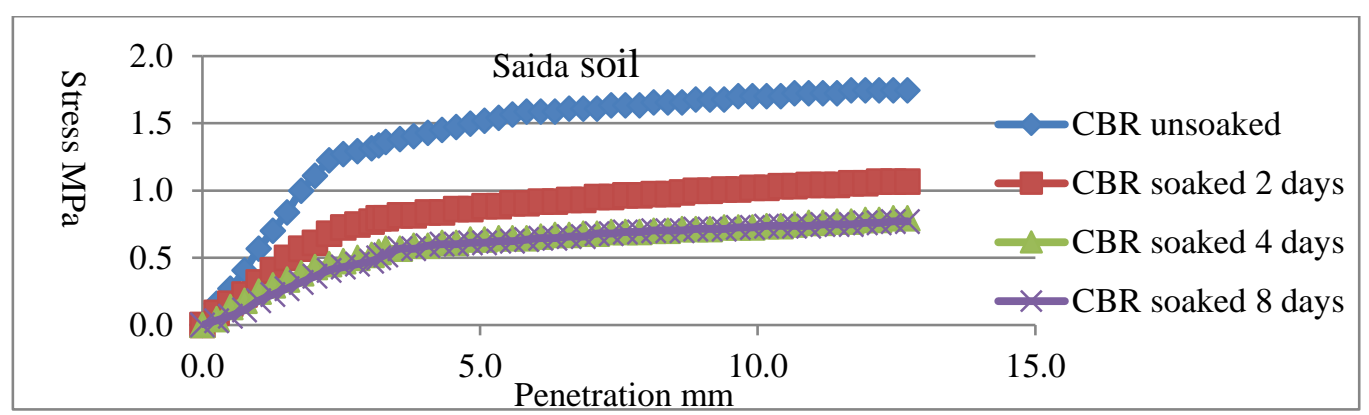

Fig. 7: CBR with different soaking periods on Saida soil.

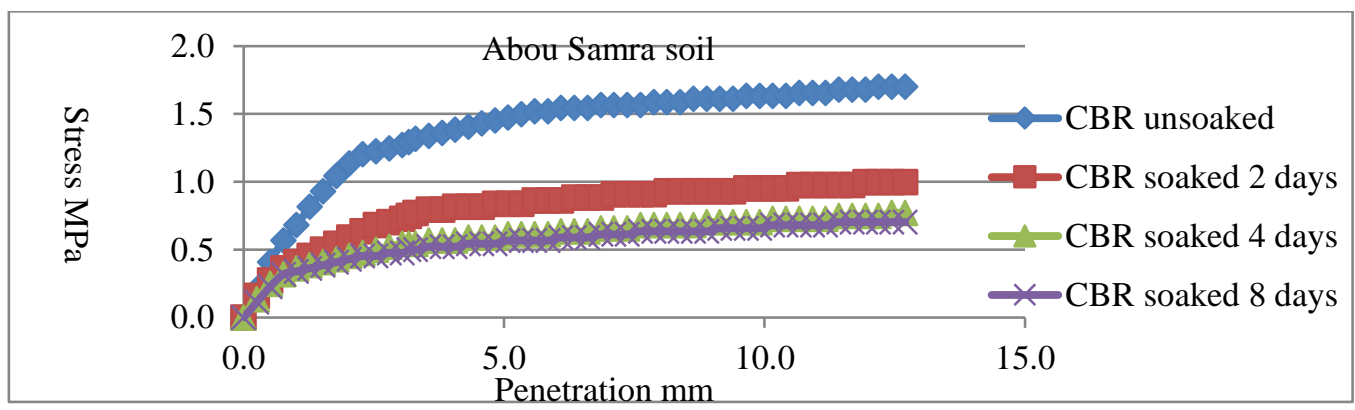

Fig. 8: CBR with different soaking periods on AbouSamra soil.

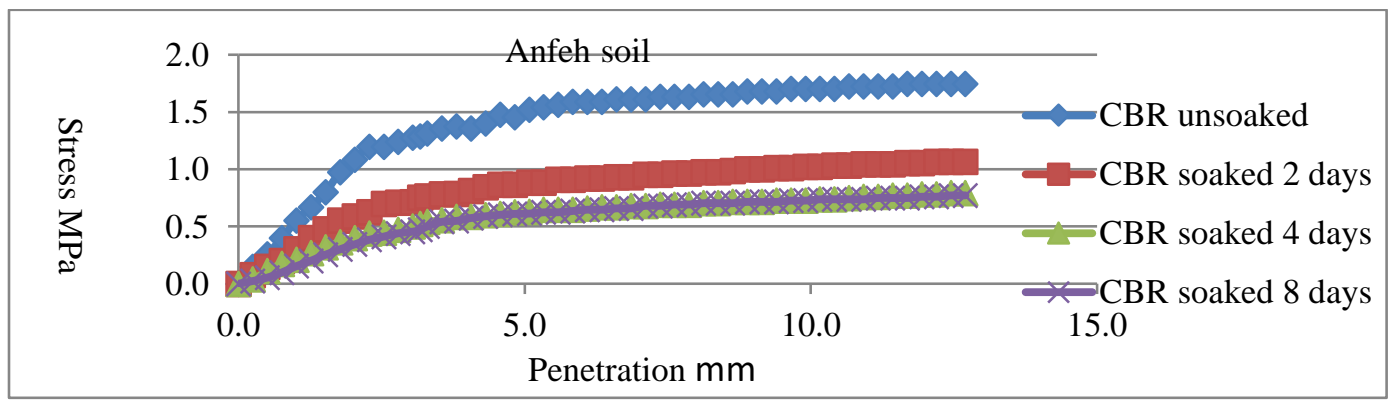

Fig. 9: CBR with different soaking periods on Anfeh soil. 


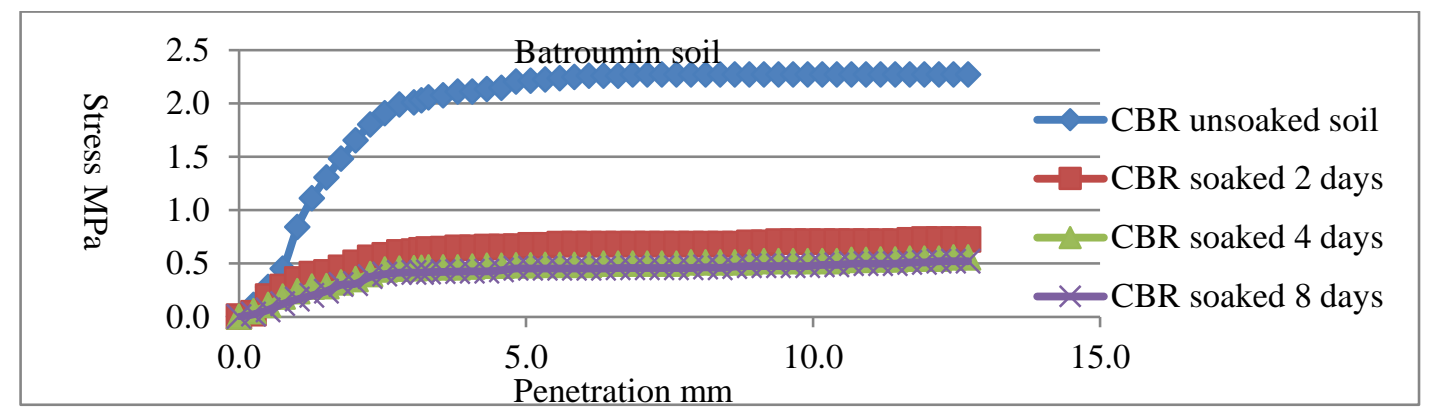

Fig. 10: CBR with different soaking periods on Batroumin soil.

\subsection{Identification Tests}

The identification tests of the nine used soil samples are very important in order to deeply analyze their behavior. We performed the Atterberg limits according to ASTM Standard D4318 [8] in order to get the liquid limit, the plastic limit, and the plasticity index. Their results are presented in Table 2.

Table 2: Identification test results on different soils.

\begin{tabular}{|c|c|c|c|c|}
\hline Soils & Location & Liquid Limit & Plastic Limit & Plasticity Index \\
\hline S1 & Barja & 65.8 & 35.4 & 30.4 \\
\hline S2 & Sahel Akkar & 64.8 & 40.6 & 24.2 \\
\hline S3 & Ghazieh & 65.4 & 37.2 & 28.2 \\
\hline S4 & Menieh & 66.3 & 35.2 & 31.1 \\
\hline S5 & MashtaHasn & 65.9 & 36.2 & 29.7 \\
\hline S7 & Saida & 65.5 & 36.6 & 28.9 \\
\hline S8 & Abi Samra & 65.9 & 35.6 & 30.3 \\
\hline S9 & Anfeh & 64.9 & 33.9 & 31.0 \\
\hline
\end{tabular}

\section{Analysis of experimental results}

In order to analyze all the experimental results performed on the soil samples, we grouped all the Proctor tests, CBR tests, and the identification tests results in Tables 3 and 4. Table 3 contains the different soils and the corresponded reduction in CBR after soaking for two, four and eight days under 0.1-inch penetration. The second column in table presents the CBR of un-soaked soil. The third, fourth, and fifth columns contain the ratio of CBR at two, four and eight soaked days to the CBR of un-soaked soil. Table 4 contains the reduction of CBR for the same soils but under 0.2 inches penetration. 
Table 3: Ratio of CBR soaked soil to CBR unsoaked soil under 0.1 “ penetration.

\begin{tabular}{|c|c|c|c|c|}
\hline \multirow{2}{*}{ Soils } & \multicolumn{4}{|c|}{0.1 “ Penetration } \\
\cline { 2 - 5 } & CBR unsoaked & $\begin{array}{c}\text { CBR 2 days soaked / } \\
\text { CBR unsoaked }\end{array}$ & $\begin{array}{c}\text { CBR 4 days soaked / } \\
\text { CBR unsoaked }\end{array}$ & $\begin{array}{c}\text { CBR 8 days soaked / } \\
\text { CBR unsoaked }\end{array}$ \\
\hline S1 & 16.44 & 0.570 & 0.430 & 0.380 \\
\hline S2 & 27.62 & 0.300 & 0.240 & 0.230 \\
\hline S3 & 20.39 & 0.419 & 0.240 & 0.234 \\
\hline S4 & 15.46 & 0.403 & 0.307 & 0.274 \\
\hline S6 & 16.11 & 0.571 & 0.489 & 0.469 \\
\hline S7 & 18.42 & 0.572 & 0.375 & 0.339 \\
\hline S8 & 18.74 & 0.491 & 0.351 & 0.316 \\
\hline S9 & 17.76 & 0.555 & 0.407 & 0.219 \\
\hline Average & 25.32 & 0.289 & 0.231 & 0.315 \\
\hline
\end{tabular}

Table 4: Ratio of CBR soaked soil to CBR unsoaked soil under 0.2 “ penetration.

\begin{tabular}{|c|c|c|c|c|}
\hline \multirow{2}{*}{ Soils } & \multicolumn{4}{|c|}{0.2 “ Penetration } \\
\cline { 2 - 5 } & CBR unsoaked & $\begin{array}{c}\text { CBR 2 days soaked / } \\
\text { CBR unsoaked }\end{array}$ & $\begin{array}{c}\text { CBR 4 days soaked / } \\
\text { CBR unsoaked }\end{array}$ & $\begin{array}{c}\text { CBR 8 days soaked / } \\
\text { CBR unsoaked }\end{array}$ \\
\hline S1 & 14.32 & 0.560 & 0.400 & 0.360 \\
\hline S2 & 21.48 & 0.440 & 0.210 & 0.205 \\
\hline S3 & 15.2 & 0.430 & 0.270 & 0.245 \\
\hline S4 & 13.44 & 0.413 & 0.319 & 0.283 \\
\hline S5 & 12.78 & 0.568 & 0.456 & 0.439 \\
\hline S7 & 14.76 & 0.581 & 0.418 & 0.403 \\
\hline S8 & 15.64 & 0.465 & 0.317 & 0.289 \\
\hline S9 & 14.32 & 0.569 & 0.406 & 0.385 \\
\hline Average & 20.19 & 0.374 & 0.198 & 0.195 \\
\hline
\end{tabular}

By analyzing the previous tables, we made the following remarks:

The CBR results on soaked samples are smaller than the CBR of un-soaked samples. This is evident once we understood the role of water inside the soil matrix. In fact, the clay matrix is known to undergo substantial strength reduction when they become saturated with water. This leads engineers to reduce as much as possible any surface or subsurface water infiltration from the road itself or adjacent lands.

The CBR reduction rate per soaking days seems to be not linear. In fact, from the previous tables, we can conclude that the dramatically reduction in CBR took place after two soaking days which ranges between $42.8 \%$ and $70 \%$. By extending the soaking period to four days, the CBR has lost only between $14.4 \%$ and $42 \%$ from the CBR obtained at two days soaking. After eight days of soaking, the CBR further lost between $2.5 \%$ and $11.6 \%$ from the CBR values obtained at four days soaking. These results may be used to understand better the ASTM requirements by imposing four days soaking period to be considered before performing the CBR experiment.

The CBR of these soils at 0.2 inches penetration had showed smaller value than the CBR of the same soils at 0.1 inch penetration. This was expected since that at 0.2 inches penetration, the excess of pore water pressure caused by the load application will be higher causing the reduction of the corresponded CBR. 
The slopes of the CBR curves from zero to $2.5 \mathrm{~mm}(0.1 \mathrm{inch})$ penetration are strongly reduced with increasing of the soaking period for all the soils. Beyond $2.5 \mathrm{~mm}$, the slopes appeared not affected by the soaking time factor. This is related to the strong and immediate effect of water on the compressibility characteristics of clay.

\section{Conclusion}

This research paper shows the strong relation between the water content of clayey soil and its mechanical strength. A large reduction in the CBR value was noticed after soaking the soils. The main reduction was registered directly after soaking at two days. By extending the soaking period of soils, the CBR reduction was found to be very low. One of the first recommendations to be given to highway engineers is to provide a powerful drain system to reduce the early infiltrated water to the pavement foundation.

\section{References}

[1] B. R. Phanikumar, K. Amrutha, "Effect of overburden pressure and degree of saturation on compressibility characteristics," International Journal of Geomechanics and Geoengineering, vol. 9, no. 1, pp. 52-62, Jul. 2013.

[2] V. Pane, R. L. Schiffman, "The permeability of clay suspensions," Geotechnique, vol. 47, no. 2, pp. 273-288, 1997.

[3] I. L. Sabri, "Study on the impact of moisture content on subgrade strength," in Proc. 5th International Symposium, Sri Lanka, 2015, pp. 71-76.

[4] H. Sarbaz, H. Ghiassian, A. A. Heshmati, "CBR strength of reinforced soil with natural fibres and considering environmental conditions," International Journal of Pavement Engineering, vol. 15, no. 7, pp. 201-209, 2006.

[5] M. A. Kamal, "Behavior of subgrade soil reinforced with geogrid," International Journal of Pavement Engineering, vol. 5, no. 4, pp. 547-588, 1965.

[6] ASTM Standard D1557-12, Standard Test Methods for laboratory compaction characteristics of soil using modified effort, ASTM international, 2001, pp. 78-88.

[7] ASTM Standard D1883, Standard Test Methods for CBR of laboratory compacted soils, ASTM international, 2001, pp. 170-177.

[8] ASTM Standard D4318, Standard Test Methods for Liquid Limit, Plastic Limit and Plasticity Index of Soils, ASTM international, 2001, pp. 561-574. 